\title{
Health behavior-related indicator of lifestyle: application in the ELSA-Brasil study
}

\author{
Ana Luísa Patrão ${ }^{1}$, Maria-da-Conceição C. Almeida ${ }^{2}$, Sheila Alvim ${ }^{1}$, Dora Chor $^{3}$ \\ and Estela M. L. Aquino ${ }^{1}$
}

\begin{abstract}
Various behaviors are considered health enhancing. Nevertheless, according to the current scientific literature, four health behaviors are considered particularly risky in view of their association with a group of chronic diseases: 1) smoking; 2) excessive alcohol consumption; 3) poor diet; and 4) lack of physical activity. Theoretically, it should be possible to make improvements to one's health by maximizing the number of healthy behaviors and minimizing the unhealthy ones. However, in reality, the different behaviors interconnect to create more complex lifestyles. Therefore, the objective of this paper is to present the construction of a lifestyle indicator based on health behaviors selected in the ELSA-Brazil study. This indicator revealed two lifestyles: less healthy and healthier lifestyles. The model proved adequate and was confirmed using latent class analysis (LCA). Agreement was 83.2 between the indicator and the LCA results, with a kappa coefficient of 0.65 . Women were more likely to have a healthier lifestyle than men, reinforcing the scientific consistency of the indicator, since this finding is in agreement with data from the scientific literature. The indicator created to define lifestyle was found to have scientific consistency and validity; therefore, its use can be recommended for future population-based studies concerning the promotion of health and healthy lifestyles.
\end{abstract}

Keywords: health education, lifestyle, behavior change

\section{Introduction}

One definition of health promotion consists of an amalgamation of health education and the organizational, economic and environmental support associated with health-promoting behavior (1). Within the social, political and economic contexts in which people are born, live, play and work, the behaviors we adopt have an effect on, and contribute to, our health. These are referred to as health behaviors $(2,3)$.

Various behaviors are health enhancing. However, as widely broadcast in the media and reflected in the therapeutic recommendations of doctors to patients and, principally, in view of the association with a set of chronic diseases, there are four specific behaviors, referred to by some authors as 'the big four', which are considered particularly relevant in the scientific literature: 1) not smoking; 2) controlled alcohol consumption; 3) eating habits; and 4) physical activity (3-7). Evidence of the association between behavior (those four behaviors in particular) and health is currently undeniable $(7,8)$, leading to another important observation: if health depends to a certain extent on behavior, then it can be improved by the action of the individual him/herself and by his/her

1. Institute of Collective Health - Federal University of Bahia, Brazil.

2. Oswaldo Cruz Foundation - Fiocruz (Bahia), Brazil.

3. Oswaldo Cruz Foundation - Fiocruz (Rio de Janeiro), Brazil.

Correspondence to: Ana Luísa Patrão, Institute of Collective Health, Rua Basílio da Gama, S/N, Salvador 40110-060, Brazil, Email: lispatrao@gmail.com

(This manuscript was submitted on 16 March 2017. Following blind peer review, it was accepted for publication on 28 January 2018)

Global Health Promotion 1757-9759; Vol 0(0): 1-8; 763148 Copyright (C) The Author(s) 2018, Reprints and permissions: http://www.sagepub.co.uk/journalsPermissions.nav DOI: 10.1177/1757975918763148 journals.sagepub.com/home/ghp 
group by modifying the factors that affect health. For example, based on the finding of the importance of these four specific behaviors, Buck and Frosini (7) developed a study in England in which they perceived that within a few years a positive change had occurred: the overall proportion of the population involved in three or four of these largely unhealthy behaviors fell significantly from around $33 \%$ of the population in 2003 to around $25 \%$ in 2008. In other words, individual change can be motivated. However, there is evidence that individual actions with respect to healthier lifestyles may be limited due to factors that influence an individual's decision-making capacity (9).

Concepts of structure and agency emerged in health promotion (10-12). Both concepts are valid in the promotion of health. On the one hand, health promotion is originally based on a critique of approaches focusing on individual lifestyles. Health promotion approaches emphasize the importance of the structure of lifestyle. On the other hand, agency is crucial for health promotion action (e.g. interventions aim at improving personal and community's skills that increase the options available to people to exercise more control over their own health and over their environments, and to make choices conducive to health) (11). There is a clear association between the way in which people live and their health; hence, it is possible to identify healthy and unhealthy lifestyles (13). Lifestyle is defined as a way of life based on identifiable patterns of behavior that are determined by the interaction between individual and personal characteristics, social relationships and socioeconomic and environmental life conditions (14). The combination of health behaviors that integrate lifestyles has been found to be associated with a very wide range of social factors that includes economic inequality, social isolation, routine stress and belonging to minority social groups, as well as factors related to employment and unemployment, stress, gender, etc. $(8,15,16)$. Nevertheless, it is a fact that, due to their importance in health, the four previously mentioned behaviors are often cited as the principal indicators with which to evaluate healthy lifestyles. Consequently, the creation of lifestyle indicators would enable the routine practice of health behaviors to be evaluated in a combined and interconnected manner, bearing in mind that these behaviors are more than the mere sum of their parts; they are interrelated and occur simultaneously, resulting in more complex lifestyles (5).
It was thus considered scientifically relevant to conduct an evaluation of possible lifestyles based on these behaviors as part of the Brazilian Longitudinal Study of Adult Health (ELSA-Brasil) in an attempt to obtain further information on issues related to health promotion in the Brazilian adult population. Currently, various studies have been conducted worldwide to investigate individual health behaviors or sets of behaviors, some as part of the ELSA-Brasil study itself (e.g. 17). Research has concentrated particularly on the issue of risk factors for disease. However, studies focused specifically on evaluating 'the big four' as an interconnected set of risk behaviors (5) and in accordance with an indicator validated to define lifestyles in the promotion of health remain sparse.

The objective of the present paper was to describe the construction of a lifestyle indicator based on the health behaviors included in the ELSA-Brasil study, the largest longitudinal study of adult health in Brazil. Its aim was to investigate the incidence of and risk factors (biological, behavioral, environmental, occupational and social risk factors) for chronic diseases, particularly cardiovascular disease and diabetes, in the adult Brazilian population.

\section{Methods}

\section{Data source}

The ELSA-Brasil cohort consists of around 15,000 active and retired civil servants (8218 women and 6887 men) of 35 to 74 years of age from six public institutes of higher education and research in the northeastern, southern and southeastern regions of Brazil. Data collection for the ELSA-Brasil study included face-to-face interviews, measurements and medical tests, which have already been described in detail in papers published by Aquino et al. (18) and Schmidt et al. (19). All the participants of the study signed an informed consent form. The internal review boards of the participating centers approved the study protocol. The baseline data from that study were used for the present analysis (18).

\section{Measures}

The variables that constitute lifestyle are:

1. Smoking. Evaluated by asking: 'Do you currently smoke?' 
Table 1. Health behaviors and their respective classification.

\begin{tabular}{|c|c|c|}
\hline \multirow[t]{2}{*}{ Health behavior } & \multicolumn{2}{|l|}{ Classification } \\
\hline & Less healthy & Healthier \\
\hline Smoking & Smokes & Does not smoke \\
\hline Alcohol consumption & $\begin{array}{l}\text { Excessive } \\
(\text { men } \geq 210 \text { g/week; women } \geq 140 \text { g/week })\end{array}$ & $\begin{array}{l}\text { Not excessive } \\
(\text { men }<210 \text { g/week; women < } 140 \text { g/week })\end{array}$ \\
\hline Physical activity & $\begin{array}{l}\text { Inactive } \\
<150 \mathrm{~min} / \text { week of moderate physical } \\
\text { activity or walking and/or }<60 \mathrm{~min} / \text { week } \\
\text { of vigorous" physical activity or } \\
<150 \text { min per week of any combination } \\
\text { of walking, moderate }{ }^{* *} \text { and vigorous } \\
\text { physical activity }\end{array}$ & $\begin{array}{l}\text { Active } \\
\geq 150 \mathrm{~min} / \text { week of moderate physical } \\
\text { activity or walking and/or } 60 \mathrm{~min} / \text { week of } \\
\text { vigorous" physical activity or } 150 \mathrm{~min} \text { per } \\
\text { week of any combination of walking, } \\
\text { moderate }\end{array}$ \\
\hline Eating habits & $\begin{array}{l}\text { No daily consumption of fruit } \\
\text { No daily consumption of greens and } \\
\text { vegetables }\end{array}$ & $\begin{array}{l}\text { Daily consumption of fruit } \\
\text { Daily consumption of greens and } \\
\text { vegetables }\end{array}$ \\
\hline
\end{tabular}

*Physical activities that demand great effort, resulting in much harder breathing than normal.

**Physical activities that demand some effort, resulting in slightly harder breathing than normal.

2. Alcohol consumption. Evaluated by asking about the amount of alcohol consumed weekly (red and white wine, bottled or draft beer, and spirits), classified in accordance with the recommendations of Duncan, Schmidt and Giugliani (20). For example, one of the questions was: 'How many glasses of red wine do you drink per week?'

3. Physical activity, measured using the recreation, sport, and leisure time physical activity domain of the long version of the International Physical Activity Questionnaire (IPAQ) (Haskell et al. (21); Brazilian version validated by Matsudo et al. (22)), which consists of six questions (For example, 'On how many days a week do you walk in your leisure time?').

4. Eating habits. Eating habits were evaluated from participants' self-reports on whether they consumed greens, vegetables and fruit at least once a day, by asking the following two questions, related to two distinct eating behaviors: (a) 'How often do you usually eat raw, boiled or sautéed greens or vegetables other than potatoes, cassava/manioc, white yam and yellow yam?' and (b) 'How often do you usually eat fruit other than in the form of fruit juices?'.

The cut-off points used to classify eating habits and smoking were based on whether or not the behavior was present. The cut-off point regarding excessive alcohol consumption was in accordance with the definitions established by Duncan, Schmidt and Giugliani (20). For physical activity, the classification adopted was that established by Haskell et al. (21). Lifestyle is classified as healthy or unhealthy and the classification of the behaviors evaluated in this study is shown in Table 1.

Investigators specifically trained for the purpose applied the research instruments. In the case of closed questions, the possible answers were read to stimulate response.

\section{Statistical analysis}

In order to create the indicator lifestyle, the presence of each health-enhancing behavior was evaluated. A score that ranged from 0 (no healthy behaviors whatsoever) to 5 (all the healthy behaviors were present) was then attributed to each participant. The scores were then dichotomized as follows: a less healthy lifestyle ( $\leq$ 2 healthy behaviors; i.e. most of the behaviors evaluated were unhealthy) and a healthier lifestyle (3-5 healthy behaviors). Next, latent class analysis (LCA) was used to classify individuals into homogenous subgroups (23) with which to identify the construct lifestyle. The latent variable resulting from the analysis was compared with the indicator, 


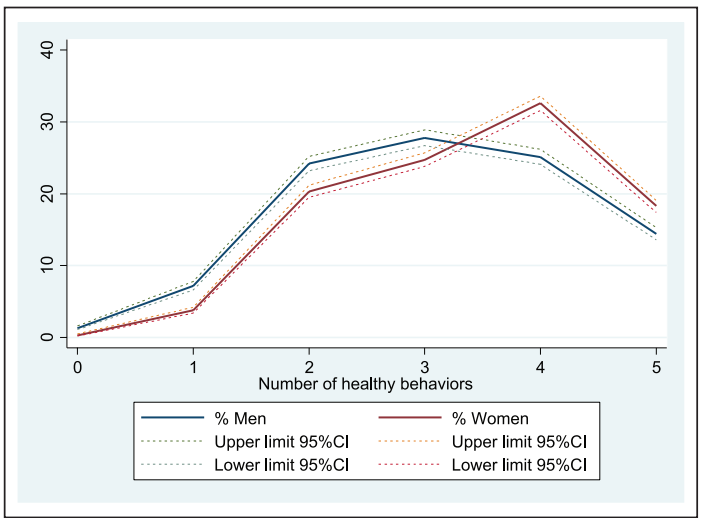

Figure 1. Percentage distribution of participants in the ELSA-Brasil study by gender, according to the number of healthy behaviors adopted.

and agreement measures and Kappa coefficients were calculated.

The data were analyzed using the STATA software package, version 12, and the MPLUS software package, version 7 .

\section{Results}

The sum of the health-related behaviors under investigation generated a lifestyle indicator that ranged from 0 (less healthy) to 5 (healthier). Overall, $0.8 \%$ of the participants were classified as having a completely unhealthy lifestyle, with no healthy behaviors present. In contrast, the lifestyle of $16.5 \%$ of the participants was considered completely healthy, with the presence of all the healthy behaviors evaluated (Figure 1). Women were more likely than men to adopt healthy behaviors, with the presence of four or five actions of healthy behaviors being more common among women than men (Figure 1). There was a steady increase in the number of men adopting healthy behaviors until reaching a total of three healthy behaviors (27.8\%), after which the proportion began to fall. Taking into account the large proportion of health enhancing behaviors, the cut-off point was established as three. At that cut-off limit, $71.8 \%$ of the participants were considered to have a healthy lifestyle: $75 \%$ of the women and $67.3 \%$ of the men.

According to LCA, the probability that the individuals in the ELSA-Brasil cohort would be distributed in two classes was high (Table 2, i.e. there are two types of health behavior patterns; entropy $=0.75$ ). Individuals adopting healthy behaviors were more likely to belong to Class II. However, the probability that individuals who did not smoke and did not drink would belong to Class I was also high. On the other hand, the probability of not practicing physical activity in leisure time was low $(<50 \%)$ in both classes.

When the results of the lifestyle indicator were compared with the result of the LCA, agreement was $83.2 \%$, with a Kappa coefficient of 0.65 (Table 3).

\section{Discussion}

The objective of the present study was to construct a lifestyle indicator, taking selected health behaviors into consideration. The lifestyle indicator created using the variables related to the four key healthrelated components (eating behavior, evaluated here from two distinct actions - fruit consumption and vegetable consumption; leisure time physical activity; smoking and alcohol consumption) was found to be adequate for the ELSA-Brasil cohort, and was confirmed in the LCA. Indeed, the LCA results also suggested the creation of two classes of health behavior. In addition, when the two types of classification were compared, agreement was found to be 83.2, with a Kappa coefficient of 0.65 , suggesting a good probability that the subjects of the different lifestyles created using the lifestyle indicator corresponded to the same subjects identified in the LCA.

In terms of gender analysis, the results are in agreement with papers published in the scientific literature that women are more likely than men to lead a healthy lifestyle (16). This is also consistent with the data shown by the indicator. Various studies have shown that men are more likely to be overweight, to smoke and to consume less healthy diets, whereas women are more committed to health-enhancing behaviors (2,24,25). The differences between genders in relation to healthenhancing behaviors and lifestyles originate to a great extent in the cumulative effects of the different social worlds in which men and women live from the moment of their birth onwards (3).

Theoretically, health can be achieved by maximizing the number of health-enhancing behaviors and minimizing the unhealthy ones. Nevertheless, in reality, the different behaviors are interconnected, resulting in more complex lifestyles 
Table 2. Parameters estimated for the model with two latent classes.

\begin{tabular}{|c|c|c|c|}
\hline \multicolumn{2}{|l|}{ Indicators } & \multirow{2}{*}{$\begin{array}{l}\text { Less healthy (Class I) } \\
\% \\
87.4\end{array}$} & \multirow{2}{*}{$\begin{array}{l}\text { Healthier } \\
\text { (Class II) } \\
\% \\
98.4\end{array}$} \\
\hline Marginal probability & & & \\
\hline Entropy & 0.75 & & \\
\hline \multicolumn{4}{|l|}{ Conditional probability } \\
\hline - Does not smoke & & 82.7 & 91.1 \\
\hline - Does not drink & & 90.2 & 94.9 \\
\hline - Eats vegetables and greens daily & & 24.4 & 79.1 \\
\hline - Eats fruit daily & & 14.4 & 100.0 \\
\hline - Performs physical activity & & 29.9 & 42.4 \\
\hline
\end{tabular}

Table 3. Results at agreement level between the classifications of the indicator and the results of LCA.

\begin{tabular}{|c|c|c|c|c|}
\hline \multirow[t]{3}{*}{ Lifestyle indicator } & \multicolumn{4}{|c|}{ Classification according to $L C A$} \\
\hline & \multicolumn{2}{|c|}{ Less healthy } & \multicolumn{2}{|c|}{ Healthier } \\
\hline & $\mathrm{n}$ & $\%$ & $n$ & $\%$ \\
\hline Less healthy & 4134 & 98.8 & 52 & 1.2 \\
\hline Healthier & 2440 & 22.9 & 8214 & 77.1 \\
\hline Agreement & $83.2 \%$ & & & \\
\hline Kappa coefficient & 0.65 & & & \\
\hline
\end{tabular}

LCA: latent class analysis.

(5). For this reason, we believe in the relevance of creating an indicator that evaluates lifestyles in an integrated and interconnected manner. Due to the importance of this issue in the investigation of chronic diseases, several studies have already focused on health behaviors; however, very few have evaluated health behaviors in an interconnected manner. One of the few studies found in this respect is the study conducted by Södergren et al. (5), which evaluated two categories of lifestyle (healthy and less healthy), with the indicator proving to be a valuable instrument for increasing knowledge on the lifestyles of the elderly Australian population. Buck and Frosini (7) studied these behaviors in an interconnected manner, not as an indicator but from the perspective of the possible combinations of these four behaviors.

These results encourage the use of this indicator created in the ELSA-Brasil study that may be applicable for both the adult Brazilian population and other populations with the same characteristics.
Several studies, including some of the studies resulting from the ELSA-Brasil, have investigated some of the health behaviors dealt with in the present study, particularly those that are detrimental to health and constitute risk factors for chronic disease (e.g. 17). Nevertheless, to the best of our knowledge, the present study is the first to create an indicator based on four behaviors (five specific actions: smoking, alcohol consumption, leisure time physical activity and dietary habits, specifically fruit consumption and vegetable consumption, analyzed here as two distinct categories) in an integrated and interconnected manner, validated using robust techniques to evaluate the effect (LCA), and within a positive perspective, i.e. health-promoting.

Here, in addition to meeting the study objective of presenting the indicator that was created, gender differences in lifestyle were investigated as a means of increasing understanding on the potential use of this indicator in future research studies. For example, in addition to gender differences, this indicator will 
allow combinations of behaviors to be identified, as well as predictors of risk for any given set of behaviors, and will allow subgroups such as different ethnic groups, age-groups or different regional populations to be evaluated for combinations of risky behaviors. The creation of this indicator could help the ELSABrasil meet its principal objective, which is to identify the factors associated with chronic diseases in Brazilian civil servants, through the degree to which it contributes to understanding risky or healthenhancing behaviors, simultaneously, in this specific population. In view of its large sample size, and the fact that the ELSA-Brasil is one of few major studies conducted in middle-income countries involving a cohort with a wide range of ages and contexts, studies on health-enhancing behaviors conducted within the ELSA-Brasil are highly likely to serve as a reference and as a guide for future research studies in Brazil and in Latin America. We believe that the creation of an easily reproducible and applicable indicator such as this one, created in a study such as the ELSA-Brasil that serves as a model for other studies, will encourage similar research to be conducted and will enable comparisons to be made regionally and internationally in a part of the world in which health-promoting studies remain sparse.

Despite the fact that the focus of this study was on creating an indicator based on health-promoting behavioral variables, it is of the utmost importance to emphasize that these behaviors and lifestyles cannot be considered without also reflecting on the social factors that influence them. The behavioral factors depend on social conditions to occur. For example, Buck and Frosini (7) developed a study based on combinations of the four key behaviors evaluated here (smoking, excessive alcohol use, poor diet, and low levels of physical activity) and observed that, from 2003 to 2008 , there was a large reduction in these risk behaviors in men and women in England. Nevertheless, those researchers found that these positive changes (e.g. better diet) occurred principally in individuals with higher education and socioeconomic levels. Rizzuto et al. (26) evaluated the factors associated with longevity in elderly Swedish individuals over 75 years of age and found that those living to over 90 years of age were significantly more committed to healthy behaviors such as physical activity and non-smoking. Associated with these behaviors were factors such as a high education level, a strong social network and leisure activities. In other words, social factors such as education and income, among others, affect behaviors and the combination of these behaviors. These issues merit attention in countries such as Brazil where social inequalities are extremely marked and related to questions of ethnicity/color. As a rule in Brazil, whites/Caucasians and Asians enjoy higher incomes and higher social status compared to blacks, individuals of mixed ethnicity and indigenous people (27). These ethnic inequalities are known to be related principally to income constraints, lower education levels, greater daily stress levels and poorer access to social opportunities and resources, which may hinder the adoption of a healthier lifestyle $(28,29)$. The creation of this indicator will also allow future studies to investigate the principal combinations of behaviors in the participants of the ELSA-Brasil study (e.g. those who practice less physical activity are also those who smoke more). In short, we believe that the creation of this life-style indicator will help identify and analyze the factors that are predictive of health behaviors in an interconnected and simultaneous manner, which is how they routinely occur in the everyday life of individuals, in the research studies that form part of the ELSA-Brasil and in other similar studies.

One limitation of the present study in particular needs to be mentioned. The behaviors selected are not the only ones involved in the concept of lifestyle. Behaviors such as hours of sleep, use of other drugs, different types of physical activity (as in commuting and at work), and sedentariness, among others, were not taken into consideration in this study. The behaviors evaluated were selected in accordance with a review of the literature, which showed that, although they are not considered unique, they are deemed central within the framework of health promotion. Furthermore, even within the ELSABrasil study, other variables would help complement the behaviors studied. For example, the data on physical activity in the ELSA-Brasil do not refer to overall physical activity, since the domains of work and household chores were not taken into consideration. Nevertheless, this is an indicator that is intended to mirror a behavioral trend towards the greater or lesser promotion of health. Here, the principal objective was to create an indicator that would reflect motivational and behavioral change in four specific behaviors. Its main advantage is its simplicity in translating a complex construct through 
a combination of direct measurements of behavior available in most studies.

\section{Conclusion}

In conclusion, the indicator created to define lifestyles proved simple, consistent and scientifically valid. Therefore, its use is encouraged in the development of population-based studies focused on promoting health and a healthy lifestyle. The authors hope that this indicator will be used in studies within the ELSA-Brasil and in other similar research studies that contribute to the prevention of chronic non-communicable diseases. These studies will then go on to influence Brazilian policies on issues including the promotion of health and healthy lifestyles, while never forgetting the social issues such as education and socioeconomic level and questions regarding infrastructure (e.g. ensuring that appropriate and safe public places are available for the practice of physical activity) that are required for this effort.

\section{Acknowledgements}

We are grateful to the entire team of the ELSA-Brasil Brazilian Longitudinal Study of Adult Health.

\section{Declaration of conflicting interests}

None declared.

\section{Funding}

The ELSA-Brasil baseline study was supported by the Brazilian Ministry of Health (Department of Science and Technology), the Brazilian Ministry of Science and Technology (a source of funding for studies and projects), and the National Council for Scientific and Technological Development $(\mathrm{CNPq})$ (grant numbers $01060010.00 \mathrm{RS}$, $01060212.00 \mathrm{BA}, 01060300.00 \mathrm{ES}, 01060278.00 \mathrm{MG}$, 01060115.00 SP, $01060071.00 \mathrm{RJ})$.

The main researcher was supported by the Coordination for the Improvement of Higher Education Personnel (CAPES - Coordenação de Aperfeiçoamento de Pessoal de Nivel Superior), through a fellowship under the program "Atração de Jovens Talentos" - Ciência sem Fronteiras (Attracting Young Talents - Science without Borders) (reference: BJT A061/2013).

\section{References}

1. Green LW, Iverson DC. School health education. Annu Rev Public Health. 1982; 3: 321-338.

2. Bennet P, Murphy S. Psicologia e Promoção da Saúde [Psychology and Health Promotion]. 1st ed. Lisboa: Climepsi; 1999.
3. Ogden J. Psicologia da Saúde [Health Psychology]. 2nd ed. Lisboa: Climepsi; 2004.

4. Duncan BB, Chor D, Aquino EML, Bensenor IM, Mill JG, Schmidt MI, et al. Chronic non-communicable diseases in Brazil: priorities for disease management and research. Rev Saude Publica. 2012; 46: 126-134.

5. Södergren M, Wanga WC, Salmon J, Ball K, Crawford D, McNaughton SA. Predicting healthy lifestyle patterns among retirement age older adults in the WELL study: a latent class analysis of sex differences. Maturitas. 2014; 77: 41-46.

6. Vrdoljak D, Markovic BB, Puljak L, Lalić DI, Kranjčević $\mathrm{K}$, Vučak J. Lifestyle intervention in general practice for physical activity, smoking, alcohol consumption and diet in elderly: a randomized controlled trial. Arch Gerontol Geriatr. 2014; 58: 160-169.

7. Buck D, Frosini F. Clustering of unhealthy behaviours over time. Implications for policy and practice. London: The King's Fund; 2012 [cited 2017 Jun 8]. Available from: https://www.kingsfund.org.uk/ publications/clustering-unhealthy-behaviours-overtime.

8. Bennet P. Introdução Clínica à Psicologia da Saúde [Introduction to Clinical and Health Psychology]. 1st ed. Lisboa: Climepsi; 2002.

9. Pearce N, Ebrahima S, McKeec M., et al. Global prevention and control of NCDs: limitations of the standard approach. J Public Health Pol. 2015; 36: 408-425.

10. Cockerham WC. Health lifestyle theory and the convergence of agency and structure. J Health Soc Behav. 2005; 46: 51-67.

11. Rütten A, Gelius F. The interplay of structure and agency in health promotion: integrating a concept of structural change and the policy dimension into a multi-level model and applying it to health promotion principles and practice. Soc Sci Med. 2011; 73: 953-959.

12. Giddens A. The constitution of society outline of the theory of structuration. Los Angeles: University of California Press; 1984.

13. Costa-Tutusaus L, Guerra-Balic M. Development and psychometric validation of a scoring questionnaire to assess healthy lifestyles among adolescents in Catalonia. BMC Public Health. 2016; 16: 1-12.

14. World Health Organization - WHO. Health Promotion Glossary. Geneva: World Health Organization; 1997.

15. Blaxter M. Health \& Lifestyles. New York: Routledge; 1990.

16. Hankonem N. Psychosocial processes of health behaviour change in a lifestyle intervention influences of gender, socioeconomic status and personality. Helsinki: National Institute for Health and Welfare; 2011.

17. Camelo LV, Giatti L, Neves JAB, Lotufo PA, Benseñor IM, Chor D, et al. Life course socioeconomic position and C-reactive protein: mediating role of health-risk behaviors and metabolic alterations. The Brazilian longitudinal study of adult health (ELSA-Brasil). PLoS One. 2014; 9: e108426. 
18. Aquino EML, Barreto SM, Bensenor IM, Carvalho MS, Chor D, Duncan BB, et al. Brazilian longitudinal study of adult health (ELSA-Brasil): objectives and design. Am J Epidemiol. 2012; 175: 315-324.

19. Schmidt MI, Duncan BB, Mill JG, Lotufo PA, Chor D, Barreto SM, et al. Cohort profile: longitudinal study of adult health (ELSA-Brasil). Int J Epidemiol. 2015; 44: 68-75.

20. Duncan BB, Schmidt MI, Giugliani ERJ. Medicina Ambulatorial: Condutas de Atenção Primária Baseada em Evidências [Ambulatory Medicine: Evidence-based Primary Care Conducts]. Porto Alegre: Artmed Editora; 2004.

21. Haskell WL, Lee IM, Pate RR, Powell KE, Blair SN, Franklin BA, et al. Physical activity and public health: updated recommendation for adults from the American College of Sports Medicine and the American Heart Association. Med Sci Sports Exerc. 2007; 39: 1423-1434.

22. Matsudo S, Araujo T, Matsudo V, Andrade D, Andrade E, Oliveira LC, et al. International physical activity questionnaire (IPAQ): study of validity and reliability in Brazil. Atividade Física \& Saúde. 2001; 6: 5-18.

23. Geiser C. Data analysis with Mplus. New York: Guilford Press; 2013.

24. Read JG, Gorman BK. Gender and health inequality. Annu Rev Sociol. 2010; 36: 371-386.

25. Sánchez-López MP, Cuellar-Flores I, Dresch V. The impact of gender roles on health. Women Health. 2012; 52: 182-196.

26. Rizzuto D, Orsini N, Qiu C, Wang HX, Fratiglioni L. Lifestyle, social factors, and survival after age 75 : population-based study. BMJ. 2012; 345: e5568.

27. Coimbra CEA Jr, Santos RV. Health, minorities and inequality: some webs of inter-relations, emphasizing indigenous peoples in Brazil. Ciência \& Saúde Coletiva. 2000; 5: 125-132.

28. North Carolina Institute of Medicine. Prevention for the Health of North Carolina: Prevention Action Plan. Morrisville: North Carolina Institute of Medicine; 2010.

29. Pampel FC, Krueger PM, Denney JT. Socioeconomic disparities in health behaviors. Annu Rev Sociol. 2010; 36: 49-370. 